\title{
Assessment of epigenetic alterations in early colorectal lesions containing BRAF mutations
}

\author{
Takeshi Sawada ${ }^{1,2, *}$, Eiichiro Yamamoto ${ }^{1,3, *}$, Hiro-o Yamano ${ }^{4, *}$, Masanori Nojima ${ }^{5}$, \\ Taku Harada ${ }^{1}$, Reo Maruyama ${ }^{1}$, Masami Ashida ${ }^{1}$, Hironori Aoki ${ }^{1}$, Hiro-o Matsushita ${ }^{4}$, \\ Kenjiro Yoshikawa ${ }^{4}$, Eiji Harada ${ }^{4}$, Yoshihito Tanaka ${ }^{4}$, Shigenori Wakita6, Takeshi \\ Niinuma ${ }^{1}$, Masahiro Kai ${ }^{1}$, Makoto Eizuka7, Tamotsu Sugai7, Hiromu Suzuki ${ }^{1}$ \\ ${ }^{1}$ Department of Molecular Biology, Sapporo Medical University School of Medicine, Sapporo, Japan \\ ${ }^{2}$ Department of Advanced Research in Community Medicine, Kanazawa University Graduate School of Medical Sciences, \\ Kanazawa, Japan \\ ${ }^{3}$ Department of Gastroenterology, Rheumatology and Clinical Immunology, Sapporo Medical University School of Medicine, \\ Sapporo, Japan \\ ${ }^{4}$ Department of Gastroenterology, Akita Red Cross Hospital, Akita, Japan \\ ${ }^{5}$ Center for Translational Research, The Institute of Medical Science, The University of Tokyo, Tokyo, Japan \\ ${ }^{6}$ Division of Cardiovascular Medicine, Department of Internal Medicine, Kanazawa University Graduate School of Medicine, \\ Kanazawa, Japan \\ ${ }^{7}$ Department of Molecular Diagnostic Pathology, Iwate Medical University School of Medicine, Morioka, Japan \\ *These authors have contributed equally to this work \\ Correspondence to: Takeshi Sawada, e-mail: tsawada@staff.kanazawa-u.ac.jp
}

Keywords: colorectal cancer, BRAF, serrated lesion, methylation, CpG island methylator phenotype

Received: December 11,2015 Accepted: April 11,2016 Published: April 27, 2016

\section{ABSTRACT}

To clarify the molecular and clinicopathological characteristics of colorectal serrated lesions, we assessed the DNA methylation of cancer-associated genes in a cohort of BRAF-mutant precancerous lesions from 94 individuals. We then compared those results with the lesions' clinicopathological features, especially colorectal subsites. The lesions included hyperplastic polyps $(n=16)$, traditional serrated adenomas (TSAs) $(n=15)$, TSAs with sessile serrated adenomas (SSAs) $(n=6)$, SSAs $(n=49)$ and SSAs with dysplasia $(n=16)$. The prevalence of lesions exhibiting the CpG island methylator phenotype (CIMP) was lower in the sigmoid colon and rectum than in other bowel subsites, including the cecum, ascending, transverse and descending colon. In addition, several cancer-associated genes showed higher methylation levels within lesions in the proximal to sigmoid colon than in the sigmoid colon and rectum. These results indicate that the methylation status of lesions with BRAF mutation is strongly associated with their location, histological findings and neoplastic pathways. By contrast, no difference in aberrant DNA methylation was observed in normal-appearing background colonic mucosa along the bowel subsites, which may indicate the absence of an epigenetic field defect.

\section{INTRODUCTION}

Recent studies have shown that colorectal cancers (CRCs) are heterogeneous diseases that derive from distinct molecular pathways $[1,2]$. A large proportion $(80-85 \%)$ of sporadic CRCs develop through accumulation of multiple genetic and epigenetic alterations, including mutation of oncogenes and tumor suppressor genes [3], chromosomal instability (CIN) and global DNA hypomethylation. The remaining $15-20 \%$ of sporadic CRCs exhibit microsatellite instability (MSI) and concurrent hypermethylation in multiple loci, which is referred to as the $\mathrm{CpG}$ island methylator phenotype (CIMP) [4] and is tightly associated with $B R A F$ mutation $[5,6]$.

Similarly, molecular and clinicopathological analysis of colorectal premalignant lesions, including conventional adenomas and serrated lesions, has provided insight into the development of CRC and its implications 
for prevention and treatment [7]. Since establishment of the pathological classification of serrated colorectal lesions as hyperplastic polyps (HPs), traditional serrated adenomas (TSAs) or sessile serrated adenomas (SSAs) [8-11], there have been several investigations of the molecular alterations within those lesions. Those studies provide evidence that SSAs are associated with $B R A F$ mutation and CIMP, and that they are precursors of MSI-positive CRCs, which preferentially locate in the proximal colon (serrated-neoplasia pathway) [6, 12-14]. TSAs are also considered to be premalignant lesions and reportedly exhibit $B R A F$ or $K R A S$ mutations and aberrant DNA methylation [11, 15-20], though their biological and clinical characteristics are not yet fully understood. One aim of the present study was to clarify the involvement of epigenetic alterations in serrated lesions.

The two-side colon theory was recently challenged by the observation that the frequencies of $B R A F$ mutation, CIMP and $M L H 1$ methylation in CRCs gradually increase along the colon, from the rectum to the ascending colon [21]. However, there have been few reported studies on the association between colorectal subsites and the clinicopathological and molecular characteristics in precancerous lesions $[22,23]$. In the present study, we also assessed the association between DNA methylation status and clinicopathological features, including tumor locations in early colorectal lesions with $B R A F$ mutation.

Epigenetic fields for cancerization (also known as "epigenetic field defects") have been reported in several cancers, including CRC [24]. Since the first report of estrogen receptor gene methylation in normal colorectal mucosa [25], DNA methylation of a number of genes in normal-appearing colorectal mucosa from patients with CRC [26-29] or a precursor lesion $[29,30]$ have been evaluated. However, the methylation status of the normal mucosa adjacent to serrated lesions has not been studied in detail. We therefore addressed this issue in $B R A F$-mutant precursor lesions.

\section{RESULTS}

\section{CIMP status and locations of $B R A F$-mutant lesions}

The clinicopathological and molecular characteristics of the early colorectal lesions with $B R A F$ mutation analyzed in this study are summarized in Tables 1 and 2 . The majority $(74 / 106,69.8 \%)$ of these lesions were located in the right colon (from the cecum to the transverse colon), while 24 lesions $(22.7 \%)$ were found in the left colon (descending and sigmoid colon), and 8 (7.5\%) were in the rectum (Table 1 ). SSAs were predominantly observed in the proximal colon, while TSAs were more prevalent in the sigmoid colon and rectum (Table 2). The CIMP statuses of the lesions in the respective bowel subsites are summarized in Figure 1. Notably, CIMP-positive lesions were located predominantly in the proximal bowel subsites, from the cecum to the
Table 1: Clinicopathological features of the $B R A F$ mutant lesions in this study

\begin{tabular}{|c|c|}
\hline Patients $(n=94)$ & \\
\hline Age (years, mean \pm SD) & $62.9 \pm 11.3$ \\
\hline \multicolumn{2}{|l|}{ Gender } \\
\hline Female & $36(38.3 \%)$ \\
\hline Male & $58(61.7 \%)$ \\
\hline \multicolumn{2}{|l|}{ Lesions (n=106) } \\
\hline \multicolumn{2}{|l|}{ Location } \\
\hline Right colon & $74(69.8 \%)$ \\
\hline Left colon & $24(22.7 \%)$ \\
\hline Rectum & $8(7.5 \%)$ \\
\hline \multicolumn{2}{|l|}{ Bowel subsites } \\
\hline Cecum & $9(8.5 \%)$ \\
\hline Ascending colon & $37(34.9 \%)$ \\
\hline Transverse colon & $28(26.4 \%)$ \\
\hline Descending colon & $7(6.6 \%)$ \\
\hline Sigmoid colon & $17(16.0 \%)$ \\
\hline Rectum & $8(7.6 \%)$ \\
\hline \multicolumn{2}{|l|}{ Morphology } \\
\hline Flat & $62(58.5 \%)$ \\
\hline Protruded & $41(38.7 \%)$ \\
\hline Flat + protruded & $3(2.8 \%)$ \\
\hline \multicolumn{2}{|l|}{ Histology } \\
\hline HP/IM & $16(15.1 \%)$ \\
\hline TSA & $15(14.2 \%)$ \\
\hline $\mathrm{TSA}+\mathrm{SSA}$ & $6(5.7 \%)$ \\
\hline SSA & $49(46.2 \%)$ \\
\hline $\mathrm{SSA}+\mathrm{CD}$ & $9(8.5 \%)$ \\
\hline $\mathrm{SSA}+\mathrm{HGD}$ & $7(6.6 \%)$ \\
\hline Conventional adenoma & $3(2.8 \%)$ \\
\hline HGD & $1(0.9 \%)$ \\
\hline
\end{tabular}

HP, hyperplastic polyp; IM, intermediate; TSA, traditional serrated adenoma; SSA, sessile serrated adenoma; CD, cytological dysplasia; HGD, high grade dysplasia

descending colon, and were significantly less frequent in the sigmoid colon and rectum (Figure 1C). Logistic regression analysis confirmed that the correlation between tumor location and CIMP status was most significant when the bowel was subdivided using the sigmoid-descending colon junction as a boundary (Table 3 ). 
Table 2: Clinicopathological and molecular characteristics of $B R A F$-mutant lesions

\begin{tabular}{|c|c|c|c|c|c|c|c|}
\hline & \multirow{2}{*}{$\begin{array}{c}\text { Total } \\
\text { number }\end{array}$} & \multicolumn{3}{|c|}{ Proximal colon } & \multicolumn{2}{|c|}{ Distal colon } & \multirow[t]{2}{*}{ Rectum } \\
\hline & & Cecum & $\begin{array}{l}\text { Ascending } \\
\text { colon }\end{array}$ & $\begin{array}{c}\text { Transverse } \\
\text { colon }\end{array}$ & $\begin{array}{l}\text { Descending } \\
\text { colon }\end{array}$ & $\begin{array}{l}\text { Sigmoid } \\
\text { colon }\end{array}$ & \\
\hline Patients & 94 & 9 & 31 & 25 & 7 & 14 & 8 \\
\hline Age (years, mean \pm SD) & $62.9 \pm 11.3$ & $63.9 \pm 8.3$ & $65.8 \pm 10.7$ & $65.1 \pm 12.9$ & $60.3 \pm 6.9$ & $56.1 \pm 12.4$ & $65.0 \pm 8.7$ \\
\hline \multicolumn{8}{|l|}{ Sex } \\
\hline Female & $36(38.3 \%)$ & 5 & 13 & 15 & 1 & 2 & 0 \\
\hline Male & $58(61.7 \%)$ & 4 & 18 & 10 & 6 & 12 & 8 \\
\hline Lesions & 106 & 9 & 37 & 28 & 7 & 17 & 8 \\
\hline \multicolumn{8}{|l|}{ Morphology } \\
\hline Flat & $62(58.5 \%)$ & 8 & 28 & 18 & 2 & 4 & 2 \\
\hline Protruded & $41(38.7 \%)$ & 1 & 8 & 9 & 5 & 13 & 5 \\
\hline Flat+protruded & $3(2.8 \%)$ & & 1 & 1 & & & 1 \\
\hline Size $(\mathrm{mm}$, mean $\pm \mathrm{SD})$ & $10.2 \pm 5.6$ & $10.3 \pm 5.8$ & $11.7 \pm 5.9$ & $11.1 \pm 5.8$ & $7.7 \pm 1.8$ & $8.2 \pm 4.9$ & $6.5 \pm 2.1$ \\
\hline \multicolumn{8}{|l|}{ Histology } \\
\hline HP/IM & $16(15.1 \%)$ & & 3 & 3 & 1 & 6 & 3 \\
\hline TSA & $15(14.2 \%)$ & & 1 & 1 & 2 & 8 & 3 \\
\hline $\mathrm{TSA}+\mathrm{SSA}$ & $6(5.7 \%)$ & & 3 & 3 & & & \\
\hline SSA & $49(46.2 \%)$ & 9 & 20 & 14 & 3 & 2 & 1 \\
\hline $\mathrm{SSA}+\mathrm{CD}$ & $9(8.5 \%)$ & & 5 & 4 & & & \\
\hline $\mathrm{SSA}+\mathrm{HGD}$ & $7(6.6 \%)$ & & 3 & 3 & 1 & & \\
\hline Conventional adenoma & $3(2.8 \%)$ & & 1 & & & 1 & 1 \\
\hline HGD & $1(0.9 \%)$ & & 1 & & & & \\
\hline \multicolumn{8}{|l|}{ CIMP status } \\
\hline Positive & $57(53.8 \%)$ & 5 & 27 & 18 & 4 & 2 & 1 \\
\hline Negative & $49(46.2 \%)$ & 4 & 10 & 10 & 3 & 15 & 7 \\
\hline \multicolumn{8}{|l|}{ MLH1 methylation } \\
\hline Positive & $10(12.9 \%)$ & 0 & 3 & 6 & 1 & 0 & 0 \\
\hline Negative & $96(87.1 \%)$ & 9 & 34 & 22 & 6 & 17 & 8 \\
\hline Adjacent normal colon & 83 & 8 & 28 & 22 & 7 & 12 & 6 \\
\hline
\end{tabular}

HP, hyperplastic polyp; IM, intermediate; TSA, traditional serrated adenoma; SSA, sessile serrated adenoma; $\mathrm{CD}$, cytological dysplasia; HGD, high grade dysplasia

We next assessed the relationship between CIMP status and the clinicopathological findings (Table 2). CIMP was detected more frequently in lesions containing SSA components (SSAs, 61.2\%; SSAs with cytological dysplasia, 66.7\%; SSA with high-grade dysplasia, $85.7 \%$; TSA with SSAs, 66.7\%) than in TSAs $(26.7 \%)$ or HPs/intermediate (IM), which is serrated lesions that did not satisfy the criteria for SSA or TSA (37.5\%) (Figure 2A). Consistent with an earlier report [23], we found a tendency for CIMP to be more prevalent among larger tumors, though this was not statistically significant (Figure 2B). 

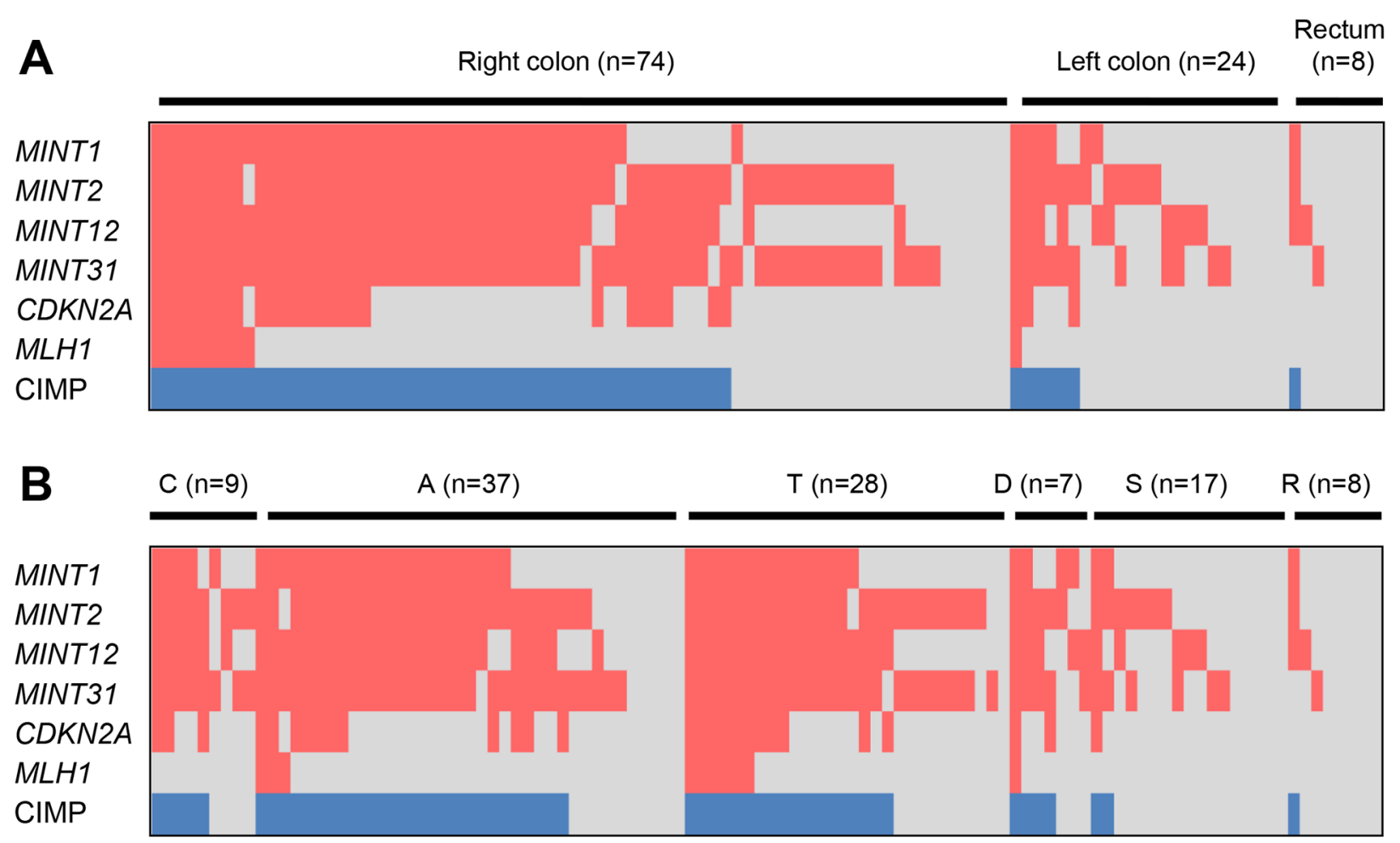

[ Methylated ] Unmethylated [CIMP positive [ CIMP negative

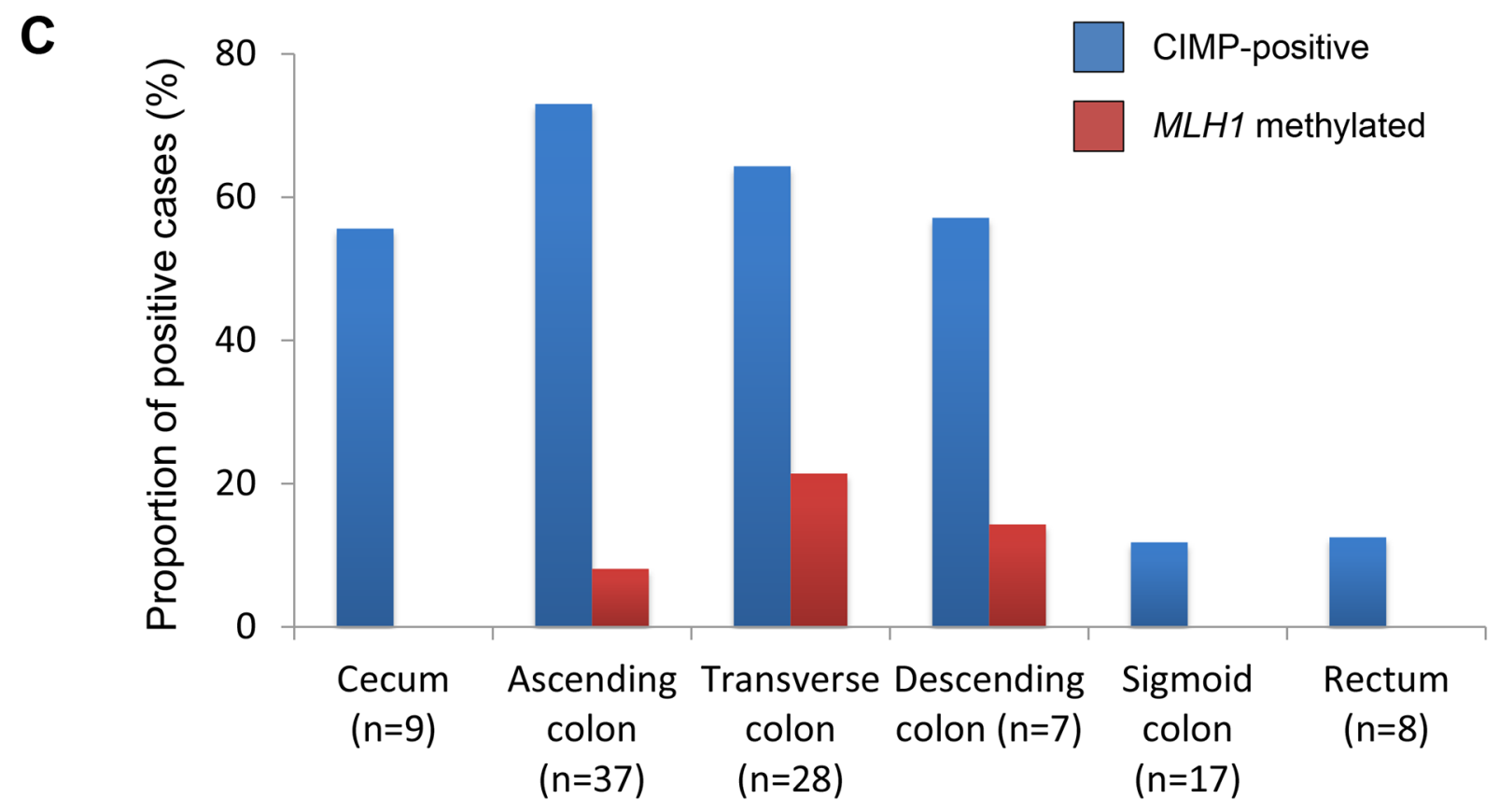

Figure 1: Methylation profiles in $\boldsymbol{B} \boldsymbol{R} \boldsymbol{A F}$-mutant lesions. A. Methylation of CIMP markers and CIMP status in lesions in the right colon (from cecum to transverse colon) and the left colon (from descending colon to sigmoid colon). B. Methylation status in $B R A F$-mutant lesions in the cecum (C) and ascending (A), transverse (T), descending (D) and sigmoid (S) colon and rectum (R). C. Frequencies of CIMP and $M L H 1$ methylation in BRAF-mutant lesions in the indicated bowel subsites. 
Table 3: Correlations between tumor location and CIMP status in $B R A F$-mutant lesions

\begin{tabular}{lcr}
\hline Demarcation & OR (95\% CI) & P \\
\hline C-A & $1.39(0.36-5.46)$ & 0.447 \\
A-T & $2.9(1.37-6.13)$ & 0.004 \\
T-D & $7.14(2.81-18.18)$ & 0.000011 \\
D-S & $13.89(3.91-50.00)$ & 0.000001 \\
S-R & $9.52(1.16-76.92)$ & 0.018 \\
\hline
\end{tabular}

C, cecum; A, ascending colon; T, transverse colon; D, descending colon; S, sigmoid colon; R, rectum

Methylation of $M L H 1$ is a hallmark of MSI in sporadic CRCs. We assessed MSI status in 24 lesions and found that the methylation status of $M L H 1$ was consistent with the MSI status in 23 of 24 lesions ( 7 of 24 were MSI-positive, while 6 were $M L H 1$ methylationpositive; $\mathrm{P}<0.001)$. We observed $M L H 1$ methylation in lesions within the ascending, transverse and descending colon, but its frequency was much lower than that of CIMP (Figure 1C). Moreover, MLH1 methylation was observed much more frequently in SSA+HGDs (85.7\%) than in other types of lesions (SSA+CDs, 6.7\%; SSAs, $4.1 \%$; TSA+SSAs, $0 \%$; TSAs, $0 \%$; HP/IMs. $0 \%$ ) (Figure 2A). These results are consistent with the earlier observations that SSAs are precursor lesions for CIMP-positive and MSI-positive CRCs, and that MLHI methylation is not an early event during colorectal tumorigenesis [6, 31, 32].

\section{Methylation of tumor-related genes in $B R A F$-mutant lesions}

We next assessed methylation of the promoter $\mathrm{CpG}$ islands of genes known to be frequently methylated in CRC [14]. We found that the methylation levels of $C D K N 2 A, I G F B P 7$, RASSF2, SOX5, $G A L N T 14, m i R-34 b / c$ and $L R P 1 B$ were significantly higher in lesions located at bowel subsites from the cecum to the descending colon than in lesions in the sigmoid colon and rectum, which was consistent with the CIMP status (Figure 3, Supplementary Figure S1). By contrast, levels of SFRP1 and SFRP2 methylation were consistently elevated in lesions throughout the entire bowel, indicating that those genes are methylated, irrespective of tumor location or the molecular subtype of the tumor.

To evaluate global DNA hypomethylation within the lesions, we analyzed levels of LINE-1 methylation, which did not correlate with bowel location (Figure $3 \mathrm{~K}$, Supplementary Figure S1K). Nor did levels of LINE-1 methylation correlate significantly with CIMP status or MLH1 methylation (data not shown).

\section{Methylation analysis of adjacent normal- appearing mucosae}

To determine whether an epigenetic field defect is involved in the development of $B R A F$-mutant lesions, we collected matched samples of the lesion and normalappearing colonic mucosa adjacent to the lesions from 83 individuals and then assessed the methylation status of three selected genes ( $m i R-34 b / c, S F R P 1$ and SFRP2) plus LINE-1. We found that methylation levels of the three genes were significantly lower in normal colonic mucosa than in the corresponding tumors (Supplementary Figure S2A-2C, S3A-2C), and that methylation did not correlate with location within the bowel (Figure 4A-4C, Supplementary Figure S4). In addition, methylation of the selected genes in normal-appearing colonic mucosa was not associated with the CIMP or MLH1 methylation status in the corresponding tumor tissues (Supplementary Figure S5A-5C, S6A-6C).

By contrast, levels of LINE-1 methylation were lower in the lesions than the adjacent normal-appearing colonic mucosa $(P=0.02$; Supplementary Figure S2D, $\mathrm{S} 3 \mathrm{D})$. Although levels of LINE-1 methylation in the normal colon did not correlate with location within the bowel or MLH1 methylation (Figure 4D, Supplementary Figure S6D), colonic tissues adjacent to CIMP-positive lesions exhibited lower LINE-1 methylation levels than those adjacent to CIMP-negative lesions $(P=0.04$, Supplementary Figure S5D). These results suggest changes in gene methylation occur in the normal colonic mucosa adjacent to tumors, but they do not strongly support the existence of an epigenetic field defect.

\section{DISCUSSION}

In this study, we comprehensively analyzed $B R A F$ mutant colorectal lesions and observed an interesting relationship between epigenetic alterations within the lesions and their bowel subsite locations. The frequency of CIMP-positive lesions significantly differed between the proximal and distal colon when the sigmoid-descending 
colon junction was used as a borderline. Similarly, levels of DNA methylation in RASSF2, SOX5, GALNT14 and $m i R-34 b / c$, four cancer-related genes, were strikingly higher in lesions located in the proximal colon (from the cecum to the descending colon) than in those in more distal subsites. This probably reflects the higher frequency of SSAs (including SSAs with dysplasia and TSAs with SSAs) in the region extending from the cecum to the descending colon. To prevent progression to $\mathrm{CRC}$, it is recommended that all serrated lesions proximal to the sigmoid colon be resected during colonoscopy [11]. Our results support that recommendation.

Recent studies suggest TSAs represent a heterogeneous category containing lesions that developed through at least two different neoplastic progression pathways that are distinct from the SSA pathway $[16,17]$. For instance, the majority of SSAs

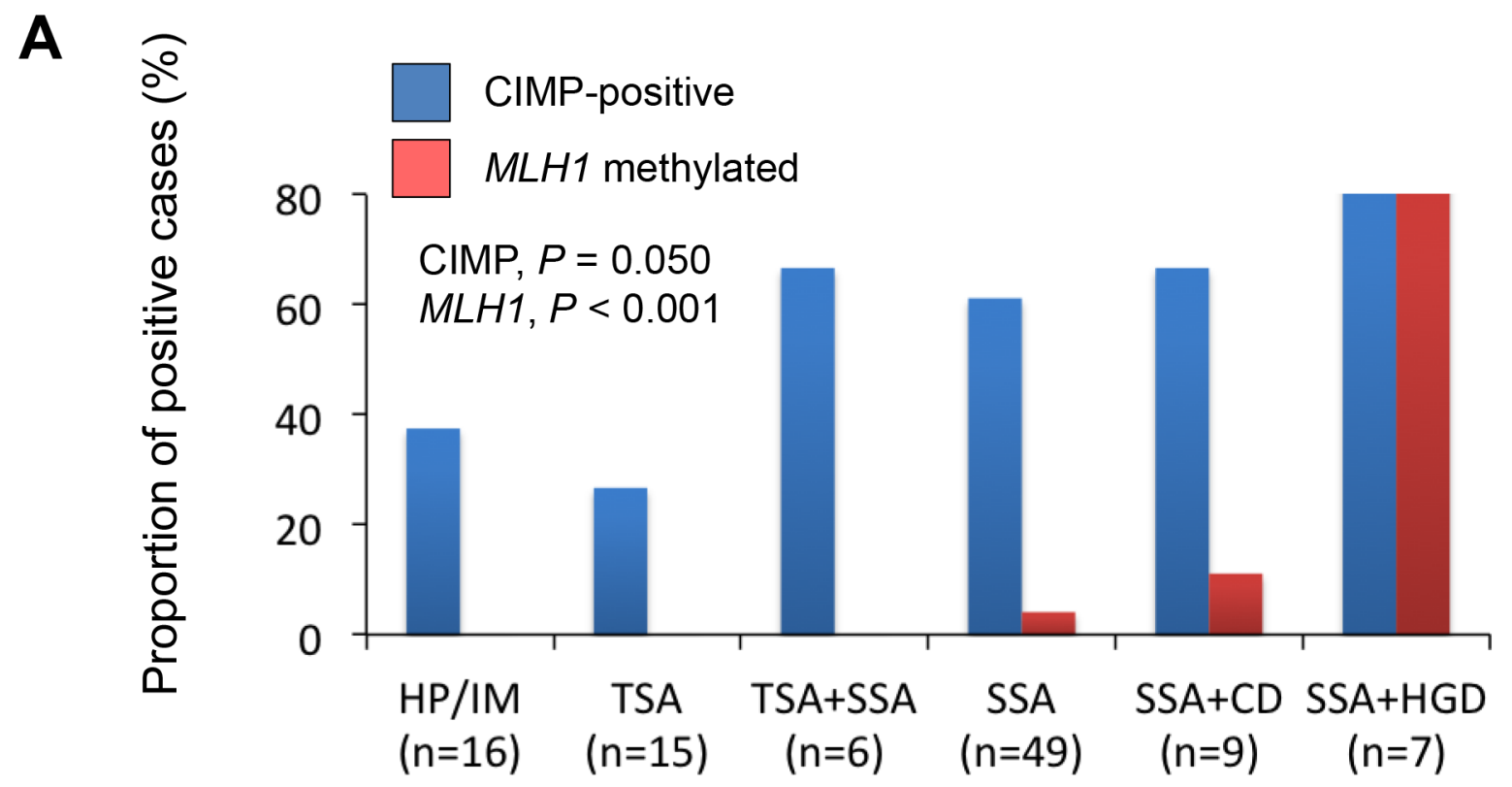

B

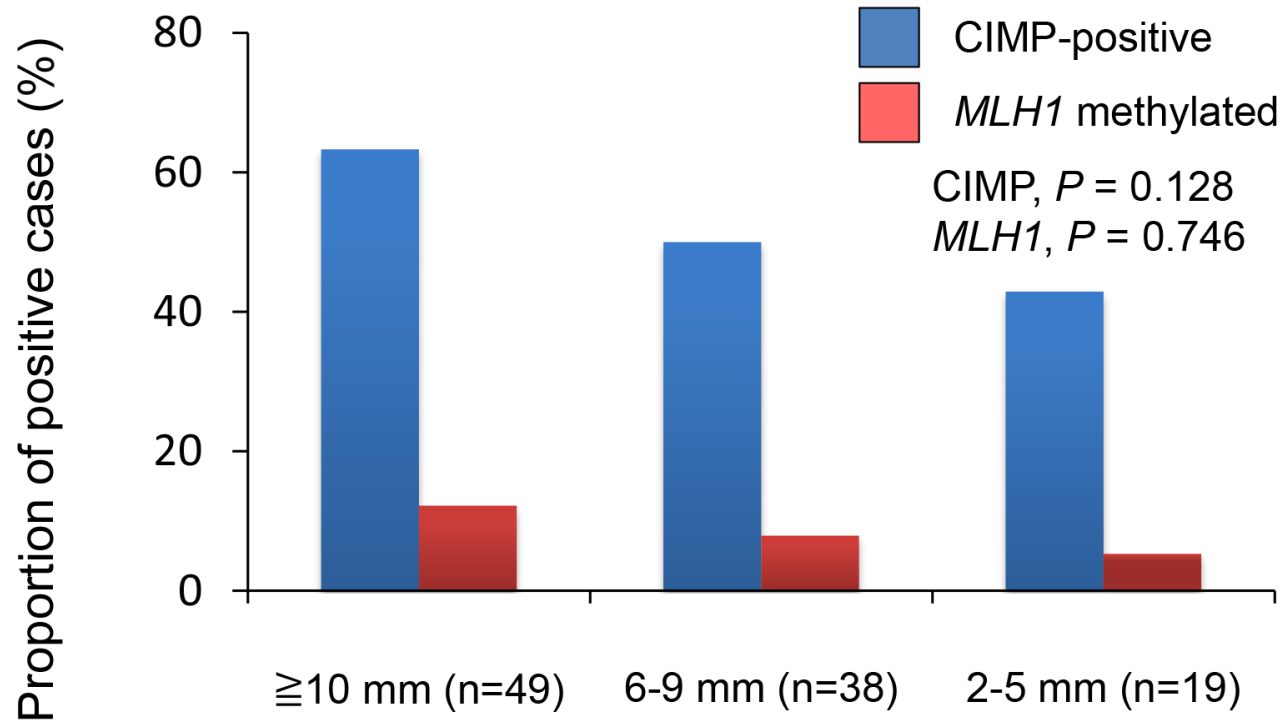

Figure 2: A. Frequencies of CIMP and MLH1 methylation in lesions with the indicated histological findings: HP, hyperplastic polyp; IM, intermediate; TSA, traditional serrated adenoma; SSA, sessile serrated adenoma; CD, cytological dysplasia; HGD, high-grade dysplasia. B. Frequencies of CIMP and $M L H 1$ methylation in $B R A F$-mutant lesions with indicated diameters. 
A CDKN2A

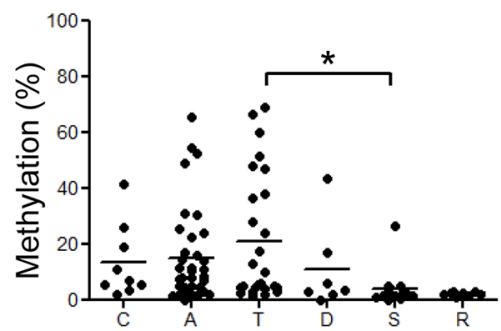

D RASSF2

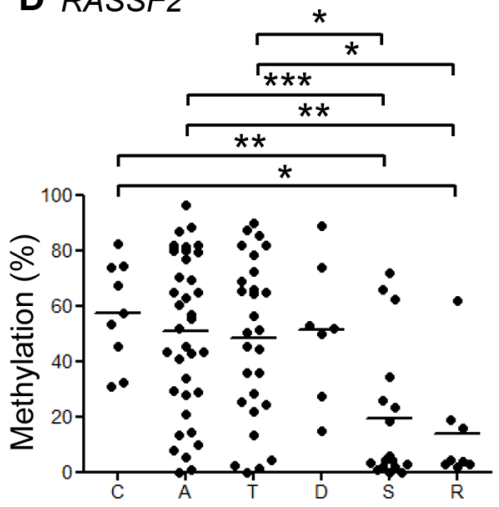

G $m i R-34 b / c$

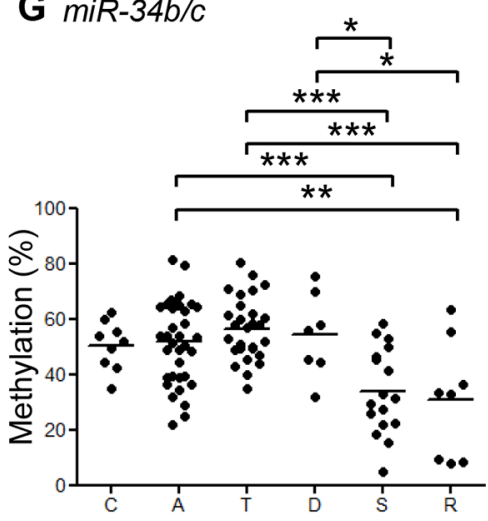

J SFRP2

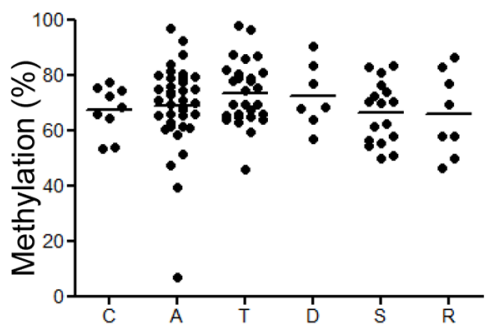

B MLH1

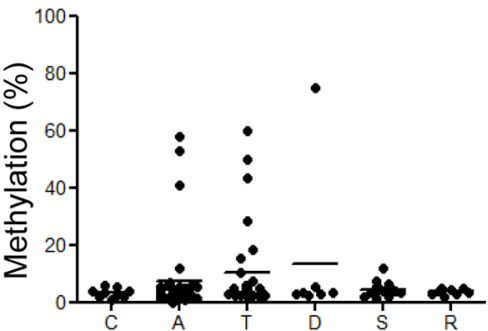

E SOX5

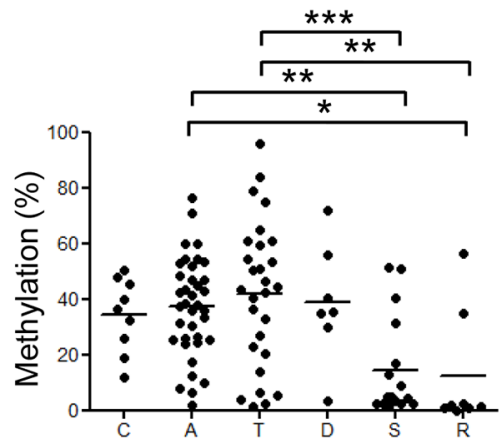

H $L R P 1 B$
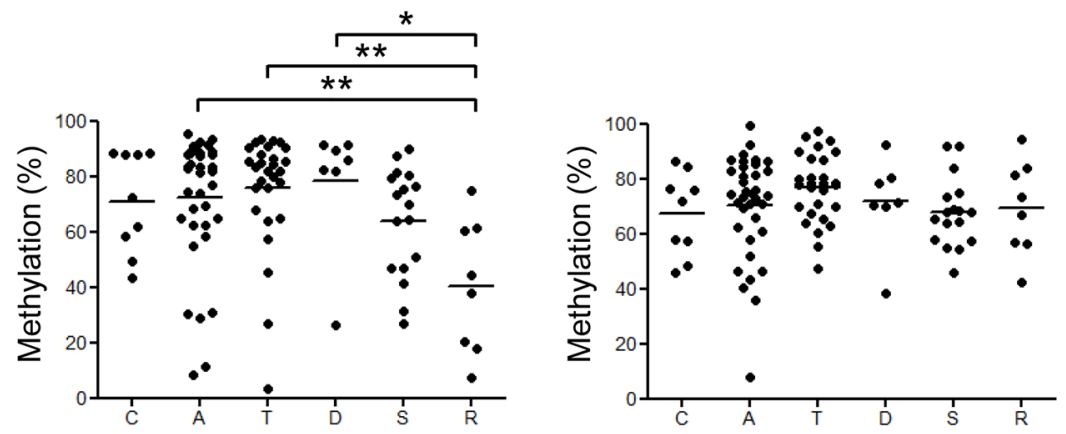

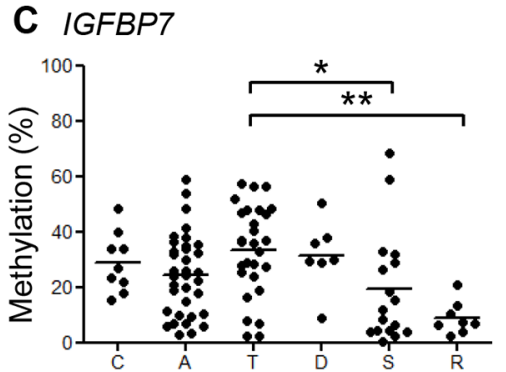

F GALNT14

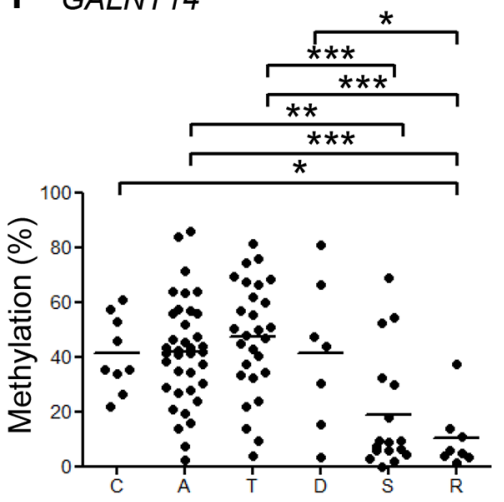

I SFRP1

K LINE-1

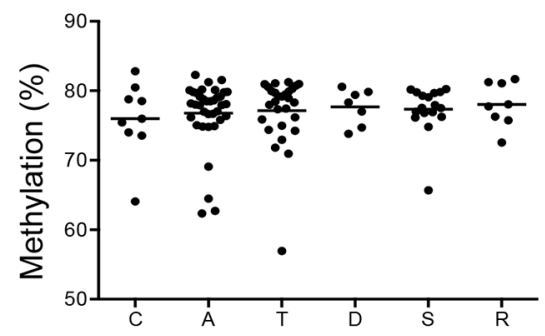

Figure 3: Summaries of the bisulfite pyrosequencing results from $B R A F$-mutant lesions. Shown are the levels of methylation of indicated genes A-H. and LINE-1 I. in lesions in the cecum (C) and ascending (A), transverse (T), descending (D) and sigmoid (S) colon and rectum (R). $* P<0.05, * * P<0.01, * * * P<0.001$. 
exhibit $B R A F$ mutations, while TSAs exhibit $K R A S$ or $B R A F$ mutations [16-19]. It is still unclear whether $B R A F$-mutant TSAs and SSAs develop into CRCs via the same neoplastic pathway, though one recent study proposed these lesions follow the same molecular pathway (BRAF mutation pathway) [17]. From the viewpoint of molecular analysis, the combination of MAP kinase pathway activation and CIMP is potentially strong evidence supporting their continued inclusion [17]. In addition, the presence of non-dysplastic precursor lesions (HPs or SSAs) associated with TSAs, which is reportedly observed in approximately $20-50 \%$ of TSAs and is significantly associated with BRAF mutation, also supports this idea [17-20]. Consistent with earlier reports [17-19], 6 of 21 TSAs (28.5\%) were associated with SSAs, and all of the lesions were in the proximal colon, while 13 of 15 TSAs without precursor lesions were located in the distal colon. Our analysis also revealed that the prevalence of CIMP in TSA+SSAs was equivalent to that in SSAs and SSA+CDs, which could contribute to the

\section{A $m i R-34 b / c$}

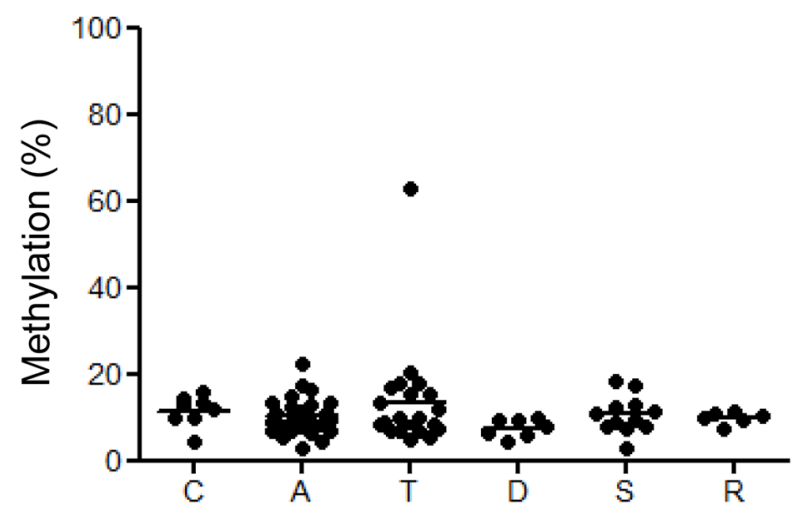

\section{SFRP2}

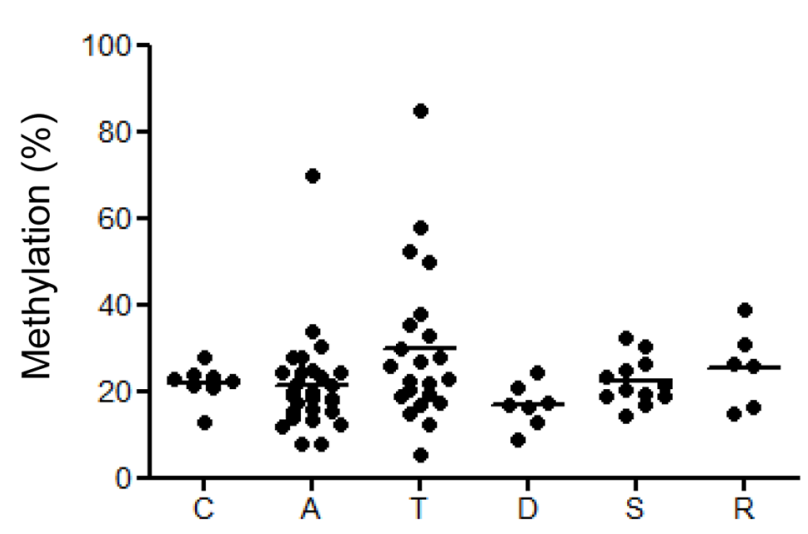

observed differences in epigenetic alterations in $B R A F$-mutant serrated lesions in different bowel subsites. It is still unclear whether TSAs arise from SSAs or whether TSA+SSAs are in the same category as SSA+CDs. A recent study showed that the SSA marker annexin A10 (ANXA10) is not expressed in TSAs or in adjacent SSAs, suggesting the precursor serrated polyps associated with TSA differ biologically from SSAs [20]. In this study, we also noted that the frequency of $C D K N 2 A$ methylation is higher in SSA+CDs (4 of 9 cases, $44.4 \%$ ) than in TSA+SSAs ( 1 of 6 cases, $16.7 \%$ ), though the difference was not statistically significant. This suggests methylation profiles may differ between the two lesions, though more comprehensive analysis of DNA methylation will be required to draw a conclusion.

Cumulative evidence suggests $B R A F$-mutant SSAs are precursors of CRCs with MSI, while $B R A F$-mutant TSAs are reportedly precursors of microsatellite-stable (MSS) CRCs $[16,17]$. In addition, recent studies showed that $\mathrm{MSI} / B R A F$ -

\section{B SFRP1}

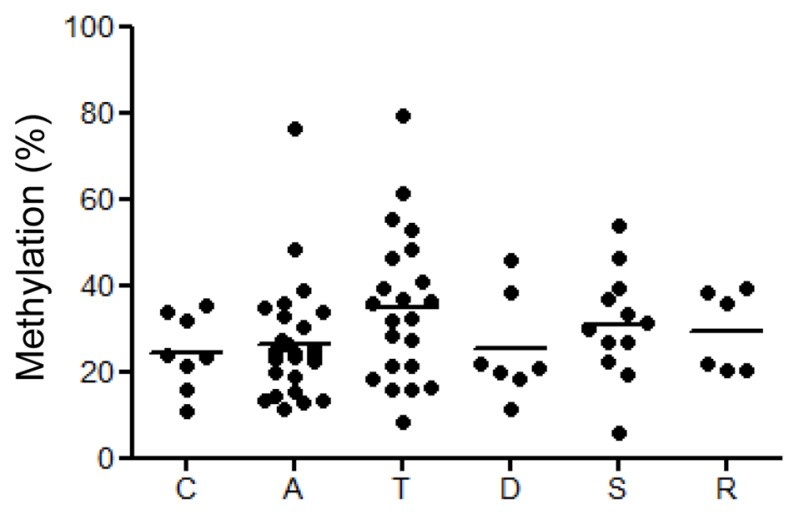

D LINE-1

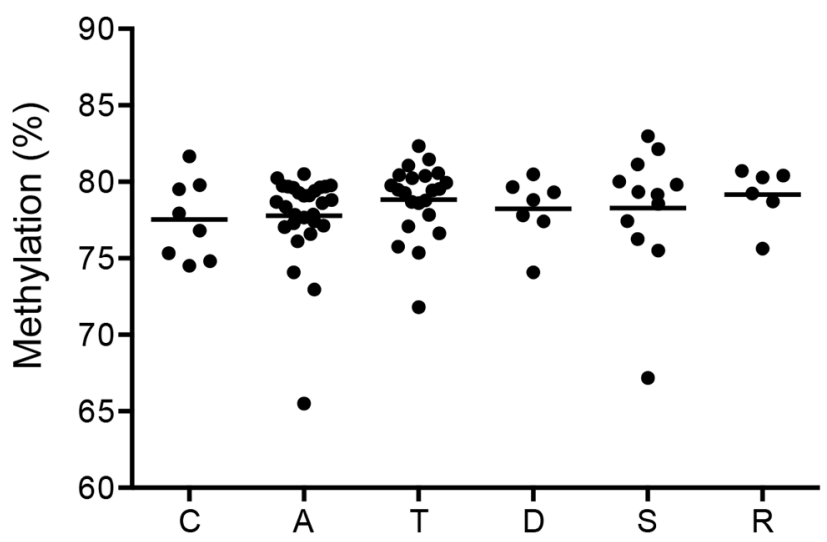

Figure 4: Summaries of bisulfite pyrosequencing results in normal-appearing mucosa adjacent to $B R A F$-mutant lesions. Shown are levels of methylation of the indicated genes A-C. and LINE-1 D. in the cecum (C) and ascending (A), transverse (T), descending (D) and sigmoid (S) colon and rectum (R). 
mutant CRCs are associated with a favorable prognosis, while $B R A F$-mutant MSS CRCs were associated with a poor one [33-35]. These results suggest that the methylation status of cancer-related genes and the tumor locations are associated with the pathological findings, carcinogenic potentials and prognoses of $B R A F$-mutant lesions.

To assess the involvement of an epigenetic field defect in the development of $B R A F$-mutant lesions, we analyzed the DNA methylation status of genes in normal colonic mucosa adjacent to the lesions. An et al. reported that levels of RASSF1A and SFRP1 methylation in normalappearing mucosa from patients with distal CRCs or polyps (conventional adenomas) were significantly higher than in proximal CRC or polyp patients [29]. In the present study, however, we did not observe significant differences in gene methylation in normal-appearing colonic mucosa among specimens from individuals with lesions in different bowel subsites, which is in contrast to the findings of Kawakami et al [28]. In addition, Worthley et al. [30] reported that the mean CIMP Z-scores calculated from the pancolorectal percent of methylated reference (PMR) using a CIMP panel (CACNA1G, IGF2, RUNX3, NEUROG1, and SOCS1) in the background mucosa of advanced proximal serrated polyps (advanced PSPs: $>1 \mathrm{~cm}$ in diameter or with advanced features, including SSA, TSA or mixed polyp) were higher than in colonic mucosa with non-advanced PSPs or without any polyps. We also compared the methylation levels in the background mucosa of advanced PSPs with the levels in background mucosa from other types of serrated polyps, but we found no significant differences (data not shown). This difference between our findings and those of Worthley et al. [30] likely reflects differences in the method of methylation analysis (MethyLight vs. pyrosequencing), lesions analyzed (all serrated lesions vs. BRAF-mutant lesions) and sampling locations (pancolorectal vs. adjacent mucosa).

The present study has several limitations, including a relatively small sample size, a limited number of lesions available for MSI analysis, the absence of normal background samples from subjects without lesions, and a limited number of genes assessed in the normal-appearing background samples. Nonetheless, we were able to make several important observations. First, methylation status in $B R A F$-mutant lesions is strongly associated with their location, histological findings and neoplastic pathways. Second, the methylation profiles in $B R A F$-mutant lesions in the proximal colon may greatly differ from those in the distal bowel when the sigmoid-descending colon junction is used as a demarcation point. Third, there were no significant differences in the methylation levels in background normal mucosa from different bowel subsites, which may indicate the absence of an epigenetic field defect for $B R A F$-mutant lesions. At present, it remains unclear whether SSAs and TSAs with $B R A F$ mutations share a common origin. Further study to clarify the spectrum of genetic and epigenetic alterations in $B R A F$ mutant lesions, including SSAs with or without dysplasia,
TSAs and TSA+SSAs, will likely provide new insight into the molecular mechanisms underlying different neoplastic pathways.

\section{MATERIALS AND METHODS}

\section{Patients and tissue samples}

Biopsy specimens from $B R A F$-mutant colorectal lesions $(\mathrm{n}=106)$ and corresponding noncancerous colonic mucosa $(n=83)$ were obtained from 94 Japanese patients who underwent colonoscopic examination at Akita Red Cross Hospital (Table 1). Informed consent was obtained from all patients before collection of the specimens, and approval of this study was obtained from the Institutional Review Board of Akita Red Cross Hospital and Sapporo Medical University.

\section{Endoscopic analysis}

High-resolution magnifying endoscopes (CF260AZI; Olympus, Tokyo, Japan) were used for all colonoscopic analyses. All lesions detected during colonoscopy were observed at high magnification using indigo carmine dye, after which biopsy specimens were collected from the lesions and adjacent normal-appearing colonic mucosa for genomic DNA extraction. The lesions were then treated by endoscopic mucosal resection, endoscopic submucosal dissection or surgical resection for histological analysis, as previously reported $[13,14]$.

\section{Histological analysis}

Histological findings for all specimens were evaluated by a pathologist (T.S.) who was blinded to the clinical and molecular information. Conventional adenoma was diagnosed using the standard criteria. Serrated lesions (HPs, SSAs and TSAs) were classified based on the criteria previously described by Torlakovic et al [9]. Mixed serrated lesions composed of SSA, TSA, CD and HGD were evaluated on the basis of each component and described as TSA $+\mathrm{SSA}, \mathrm{SSA}+\mathrm{CD}$ or SSA+HGD. The clinicopathological features of the lesions are summarized in Table 2, and salient histopathological features of the major polyp subtypes are shown in Figure 5. Tumor locations were classified as cecum, ascending colon, transverse colon, descending colon, sigmoid colon and rectum (rectosigmoid was classified into sigmoid colon).

\section{Mutation analysis}

Genomic DNA was extracted using the standard phenol-chloroform procedure. Mutation in codon 600 of $B R A F$ was examined by pyrosequencing using a $B R A F$ pyro kit (Qiagen, Hiden, Germany) according to the manufacturer's instructions. 


\section{DNA methylation analysis}

DNA methylation was analyzed using bisulfite pyrosequencing as described previously [36]. Briefly, genomic DNA $(1 \mu \mathrm{g})$ was modified with sodium bisulfite using an EpiTect Bisulfite kit (Qiagen). Pyrosequencing

A

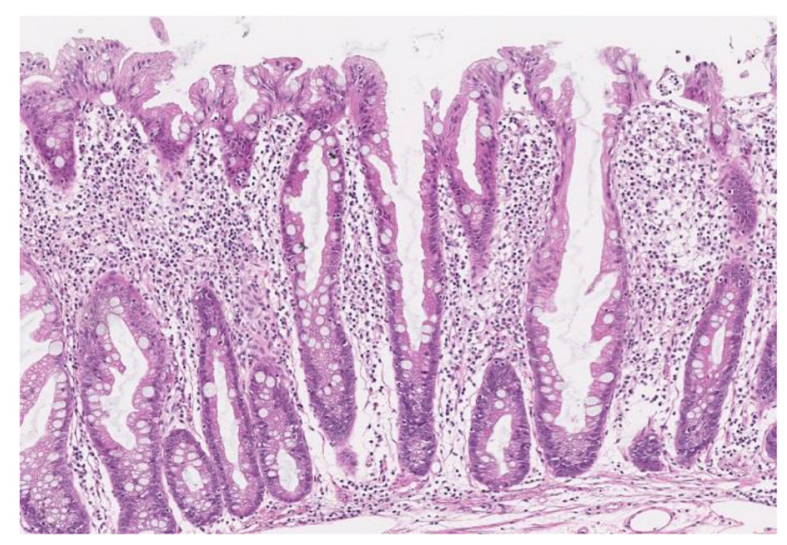

C

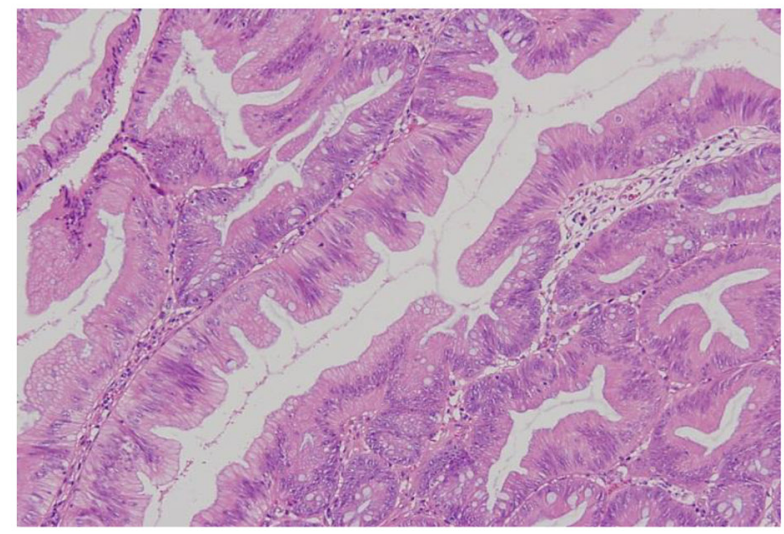

E

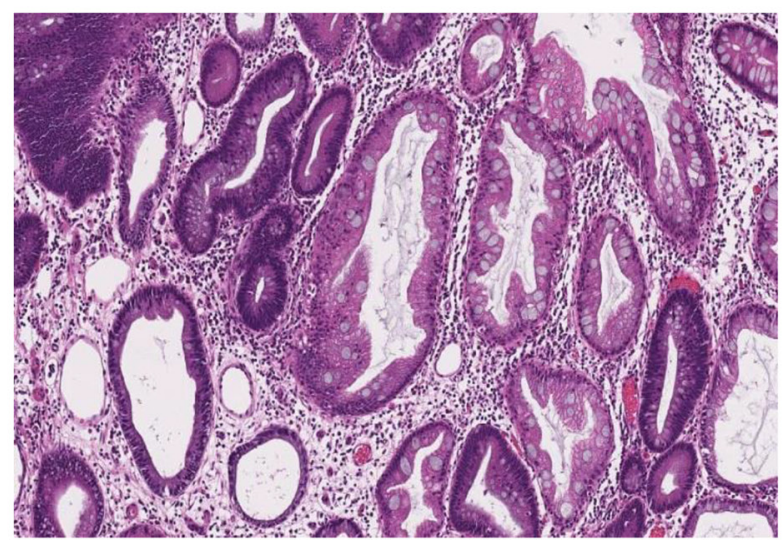

was then carried out using a PSQ 96MA system (Qiagen) with a Pyro Gold Reagent kit (Qiagen), and the results were analyzed using Pyro Q-CpG software (Qiagen). A cutoff value of $15 \%$ was used to define genes as methylation-positive. Tumors were defined as CIMPpositive when methylation was detected in three or more

B

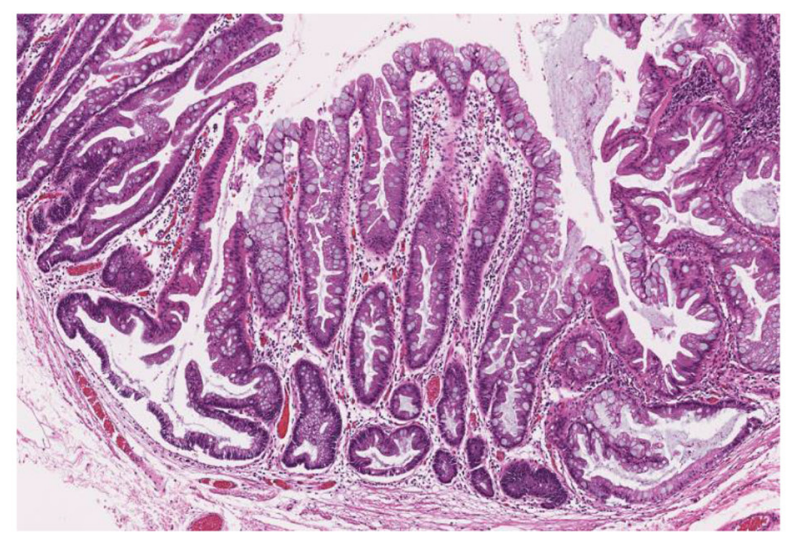

D

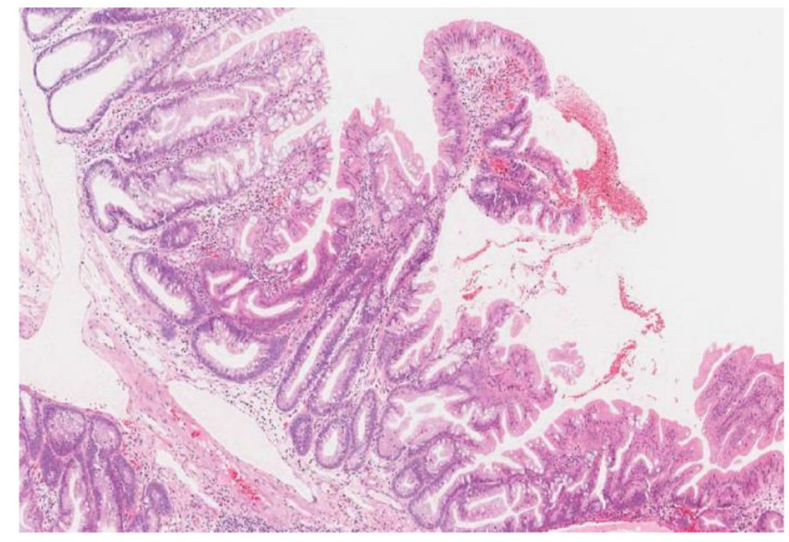

$\mathbf{F}$

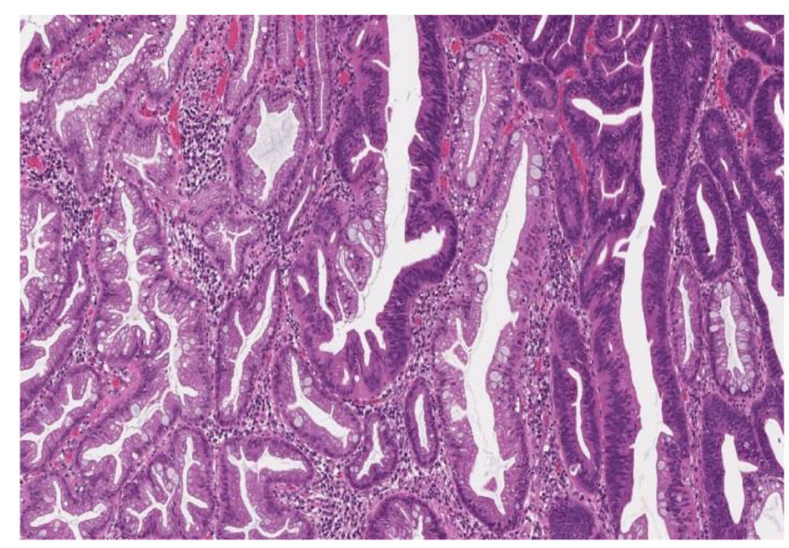

Figure 5: Representative histopathological images of the major serrated lesion subtypes. A. Hyperplastic polyp (HP). B. Sessile serrated adenoma (SSA). C. Traditional serrated adenoma (TSA). D. TSA with SSA (TSA+SSA). E. SSA with cytological dysplasia (SSA+CD). F. SSA with high-grade dysplasia (SSA+HGD). 
loci out of five classic CIMP markers (MINT1, MINT2, MINT12, MINT31 and MLH1) and CDKN2A (p16). Methylation of LRP1B, SOX5, GALNT14, RASSF2, IGFBP7, miR-34b/c, SFRP1, SFRP2 and long interspersed nucleotide elements (LINE-1) was also analyzed using bisulfite pyrosequencing. Primer sequences were as previously reported [14, 37].

\section{MSI analysis}

MSI was assessed as described previously [38]. MSI status was determined by examining a panel of 5 microsatellite markers (BAT25, BAT26, D5S346, D2S123, D17S250) [39]. Lesions were defined as MSI-positive when two or more markers showed instability.

\section{Statistical analysis}

Continuous data were analyzed using $t$-tests (for two groups) or ANOVA with a post hoc Tukey's HSD test (for more than two groups). Fisher's exact test and logistic regression were performed to assess the association between categorical variables. $P<0.05$ was considered statistically significant. All statistical analyses were performed using SPSS 20 (IBM Corporation, Somers, NY) and GraphPad Prism 6 (GraphPad Software, La Jolla, CA).

\section{ACKNOWLEDGMENTS}

The authors dedicate this manuscript to the memory of Dr. Minoru Toyota. The authors also thank Dr. William F. Goldman for editing the manuscript.

\section{FUNDING}

This study was supported in part by a Grant-inAid for Scientific Research (C) from the Japan Society for Promotion of Science (E. Yamamoto, T. Sawada), a Grant-in-Aid from the Japanese Foundation for Research and Promotion of Endoscopy (T. Sawada), and a Grant-inAid for Scientific Research (B) from the Japan Society for Promotion of Science (H. Suzuki).

\section{CONFLICTS OF INTEREST}

All authors declare no conflicts of interest.

\section{REFERENCES}

1. Grady WM, Carethers JM. Genomic and epigenetic instability in colorectal cancer pathogenesis. Gastroenterology. 2008; 135: 1079-1099.

2. Issa JP. Colon cancer: It's CIN or CIMP. Clin Cancer Res. 2008; 14: 5939-5940.
3. Fearon ER, Vogelstein B. A genetic model for colorectal tumorigenesis. Cell. 1990; 61: 759-767.

4. Toyota M, Ahuja N, Ohe-Toyota M, Herman JG, Baylin $\mathrm{SB}$, Issa JP. CpG island methylator phenotype in colorectal cancer. Proc Natl Acad Sci U S A. 1999; 96: 8681-8686.

5. Weisenberger DJ, Siegmund KD, Campan M, Young J, Long TI, Faasse MA, Kang GH, Widschwendter M, Weener D, Buchanan D, Koh H, Simms L, Barker M, et al. $\mathrm{CpG}$ island methylator phenotype underlies sporadic microsatellite instability and is tightly associated with $B R A F$ mutation in colorectal cancer. Nat Genet. 2006; 38: 787-793.

6. Kambara T, Simms LA, Whitehall VLJ, Spring KJ, Wynter CVA, Walsh MD, Barker MA, Arnold S, McGivern A, Matsubara N, Tanaka N, Higuchi T, Young J, et al. BRAF mutation is associated with DNA methylation in serrated polyps and cancers of the colorectum. Gut. 2004; 53: 1137-1144.

7. Lochhead P, Chan AT, Giovannucci E, Fuchs CS, Wu K, Nishihara R, O'Brien M, Ogino S. Progress and opportunities in molecular pathological epidemiology of colorectal premalignant lesions. Am J Gastroenterol. 2014; 109: 1205-1214.

8. Longacre TA, Fenoglio-Preiser CM. Mixed hyperplastic adenomatous polyps/serrated adenomas. A distinct form of colorectal neoplasia. Am J Surg Pathol. 1990; 14: 524-537.

9. Torlakovic E, Skovlund E, Snover DC, Torlakovic G, Nesland JM. Morphologic reappraisal of serrated colorectal polyps. Am J Surg Pathol. 2003; 27: 65-81.

10. Snover DC, Jass JR, Fenoglio-Preiser C, Batts KP. Serrated polyps of the large intestine: a morphologic and molecular review of an evolving concept. Am J Clin Pathol. 2005; 124: 380-391.

11. Rex DK, Ahnen DJ, Baron JA, Batts KP, Burke CA, Burt RW, Goldblum JR, Guillem JG, Kahi CJ, Kalady MF, O'Brien MJ, Odze RD, Ogino S, et al. Serrated lesions of the colorectum: review and recommendations from an expert panel. Am J Gastroenterol. 2012; 107: 1315-1329.

12. Spring KJ, Zhao ZZ, Karamatic R, Walsh MD, Whitehall VLJ, Pike T, Simms LA, Young J, James M, Montgomery GW, Appleyard M, Hewett D, Togashi K, et al. High prevalence of sessile serrated adenomas with $B R A F$ mutations: a prospective study of patients undergoing colonoscopy. Gastroenterology. 2006; 131: 1400-1407.

13. Kimura T, Yamamoto E, Yamano HO, Suzuki H, Kamimae S, Nojima M, Sawada T, Ashida M, Yoshikawa K, Takagi R, Kato R, Harada T, Suzuki R, et al. A novel pit pattern identifies the precursor of colorectal cancer derived from sessile serrated adenoma. Am J Gastroenterol. 2012; 107 : 460-469.

14. Yamamoto E, Suzuki H, Yamano HO, Maruyama R, Nojima M, Kamimae S, Sawada T, Ashida M, Yoshikawa K, Kimura T, Takagi R, Harada T, Suzuki R, et al. Molecular dissection of premalignant colorectal lesions 
reveals early onset of the $\mathrm{CpG}$ island methylator phenotype. Am J Pathol. 2012; 181: 1847-1861.

15. Yi C, Huang Y, Yu X, Li X, Zheng S, Ding K, Xu J. Clinicopathologic distributeon of KRAS and BRAF mutations in a Chinese population with colorectal cancer precursor lesions. Oncotarget 2016 Feb 19. [Epub ahead of print]. doi: 10.18632/oncotarget.7504.

16. Tsai JH, Liau JY, Lin YL, Lin LI, Cheng YC, Cheng ML, Jeng YM. Traditional serrated adenoma has two pathways of neoplastic progression that are distinct from the sessile serrated pathway of colorectal carcinogenesis. Mod Pathol. 2014; 27: 1375-1385.

17. Bettington ML, Walker NI, Rosty C, Brown IS, Clouston AD, McKeone DM, Pearson SA, Klein K, Leggett BA, Whitehall VLJ. A clinicopathological and molecular analysis of 200 traditional serrated adenomas. Mod Pathol. 2015; 28: 414-427.

18. Kim KM, Lee EJ, Kim YH, Chang DK, Odze RD. KRAS mutations in traditional serrated adenomas from Korea herald an aggressive phenotype. Am J Surg Pathol. 2010; 34: 667-675.

19. Kim MJ, Lee EJ, Suh JP, Chun SM, Jang SJ, Kim DS, Lee DH, Lee SH, Youk EG. Traditional serrated adenoma of the colorectum. Clinicopathologic implications and endoscopic findings of the precursor lesions. Am J Clin Pathol. 2013; 140: 898-911.

20. Wiland HO IV, Shadrach B, Allende D, Carver P, Goldblum JR, Liu X, Patil DT, Rybicki LA, Pai RK. Morphologic and molecular characterization of traditional serrated adenomas of the distal colon and rectum. Am J Surg Pathol. 2014; 38: 1290-1297.

21. Yamauchi M, Morikawa T, Kuchiba A, Imamura Y, Qian ZR, Nishihara R, Liao X, Waldron L, Hoshiba Y, Huttenhower C, Chan AT, Giovannucci E, Fuchs C, et al. Assessment of colorectal cancer molecular features along bowel subsites challenges the conception of distinct dichotomy of proximal versus distal colorectum Gut. 2012; 61: 847-854.

22. Ito M, Mitsuhashi $\mathrm{K}$, Igarashi $\mathrm{H}$, Nosho $\mathrm{K}$, Naito $\mathrm{T}$, Yoshii S, Takahashi H, Fujita M, Sukawa Y, Yamamoto E, Takahashi T, Adachi Y, Nojima M, et al. MicroRNA-31 expression in relation to $B R A F$ mutation, $\mathrm{CpG}$ island methylation and colorectal continuum in serrated lesions. Int J Cancer. 2014; 135: 2507-2515.

23. Burnett-Hartman AN, Newcomb PA, Potter JD, Passarelli MN, Phipps AI, Wurscher MA, Grady WM, Zhu LC, Upton MP, Makar KW. Genomic aberrations occurring in subsets of serrated colorectal lesions but not conventional adenomas. Cancer Res. 2013; 73: 2863-2872.

24. Ushijima T. Epigenetic field for cancerization. J Biochem Mol Biol. 2007; 40: 142-150.

25. Issa JP, Ottaviano YL, Celano P, Hamilton SR, Davidson NE, Baylin SB. Methylation of the oestrogen receptor $\mathrm{CpG}$ island links ageing and neoplasia in human colon. Nat Genet. 1994; 7: 536-540.
26. Suzuki H, Watkins DN, Jair KW, Schuebel KE, Markowitz SD, Chen WD, Pretlow TP, Yang B, Akiyama Y, van Engeland M, Toyota M, Tokino T, Hinoda Y, et al. Epigenetic inactivation of SFRP genes allows constitutive WNT signaling in colorectal cancer. Nat Genet. 2004; 36 : 417-422.

27. Shen L, Kondo Y, Rosner GL, Xiao L, Hernandez NS, Vilaythong J, Houlihan PS, Krouse RS, Prasad AR, Einspahr JG, Buckmeier J, Alberts DS, Hamilton SR, et al. MGMT promoter methylation and field defect in sporadic colorectal cancer. J Natl Cancer Inst. 2005; 97: 1330-1338.

28. Kawakami K, Ruszkiewicz A, Bennett G, Moore J, Grieu F, Watanabe G, Iacopetta B. DNA hypermethylation in the normal colonic mucosa of patients with colorectal cancer. Br J Cancer. 2006; 94: 593-598.

29. An B, Kondo Y, Okamoto Y, Shinjo K, Kanemitsu Y, Komori K, Hirai T, Sawaki A, Tajika M, Nakamura T, Yamao K, Yatabe Y, Fujii M, et al. Characteristic methylation profile in $\mathrm{CpG}$ island methylator phenotypenegative distal colorectal cancers. Int J Cancer. 2010; 127: 2095-2105.

30. Worthley DL, Whitehall VLJ, Buttenshaw RL, Irahara N, Greco SA, Ramsnes I, Mallitt KA, Le Leu RK, Winter J, Hu Y, Ogino S, Young GP, Leggett BA. DNA methylation within the normal colorectal mucosa is associated with pathway-specific predisposition to cancer. Oncogene. 2010; 29: 1653-1662.

31. Iino H, Jass JR, Simms LA, Young J, Leggett B, Ajioka Y, Watanabe H. DNA microsatellite instability in hyperplastic polyps, serrated adenomas, and mixed polyps: a mild mutator pathway for colorectal cancer? J Clin Pathol. 1999; 52: 5-9.

32. O'Brien MJ, Yang S, Mack C, Xu H, Huang CS, Mulcahy E, Amorosino M, Farraye FA. Comparison of microsatellite instability, $\mathrm{CpG}$ island methylation phenotype, BRAF and KRAS status in serrated polyps and traditional adenomas indicates separate pathways to distinct colorectal carcinoma end points. Am J Surg Pathol. 2006; 30: 1491-1501.

33. Lochhead P, Kuchiba A, Imamura Y, Liao X, Yamauchi M, Nishihara R, Qian ZR, Morikawa T, Shen J, Meyerhardt JA, Fuchs CS, Ogino S. Microsatellite instability and $B R A F$ mutation testing in colorectal cancer prognostication. J Natl Cancer Inst. 2013; 105: 1151-1156.

34. Phipps AI, Limburg PJ, Baron JA, Burnett-Hartman AN, Weisenberger DJ, Laird PW, Sinicrope FA, Rosty C, Buchanan DD, Potter JD, Newcomb PA. Association between molecular subtypes of colorectal cancer and patient survival. Gastroenterology. 2015; 148: 77-87.

35. Sinicrope FA, Shi Q, Smyrk TC, Thibodeau SN, Dienstmann R, Guinney J, Bot BM, Tejpar S, Delorenzi M, Goldberg RM, Mahoney M, Sargent DJ, Alberts SR. Molecular markers identify subtypes of stage III colon cancer associated with patient outcomes. Gastroenterology. 2015; 148: 88-99. 
36. Toyota M, Suzuki H, Sasaki Y, Maruyama R, Imai K, Shinomura Y, Tokino T. Epigenetic silencing of microRNA$34 \mathrm{~b} / \mathrm{c}$ and $B$-cell translocation gene 4 is associated with $\mathrm{CpG}$ island methylation in colorectal cancer. Cancer Res. 2008; 68: 4123-4132.

37. Yamamoto E, Toyota M, Suzuki H, Kondo Y, Sanomura T, Murayama Y, Ohe-Toyota M, Maruyama R, Nojima M, Ashida M, Fujii K, Sasaki Y, Hayashi N, et al. LINE-1 hypomethylation is associated with increased $\mathrm{CpG}$ island methylation in Helicobacter pylori-related enlarged-fold gastritis. Cancer Epidemiol Biomarkers Prev. 2008; 17: 2555-2564.
38. Sugai T, Habano W, Endoh M, Konishi Y, Akasaka R, Toyota M, Yamano H, Koeda K, Wakabayashi G, Suzuki K. Molecular analysis of gastric differentiated-type intramucosal and submucosal cancers. Int J Cancer. 2010; 127: 2500-2509.

39. Boland CR, Thibodeau SN, Hamilton SR, Sidransky D, Eshleman JR, Burt RW, Meltzer SJ, Rodriguez-Bigas MA, Fodde R, Ranzani GN, Srivastava S. A national cancer institute workshop on microsatellite instability for cancer detection and familial predisposition: development of international criteria for the determination of microsatellite instability in colorectal cancer. Cancer Res. 1998; 58: 5248-5278. 